\title{
Stabilized Low-n Amyloid- Oligomers Induce Robust Novel Object Recognition Deficits Associated with Inflammatory, Synaptic, and GABAergic Dysfunction in the Rat DOI:
}

10.3233/JAD-170489

\section{Document Version \\ Accepted author manuscript}

Link to publication record in Manchester Research Explorer

Citation for published version (APA):

Watremez, W., Jackson, J., Almari, B., McLean, S. L., Grayson, B., Neill, J. C., Fischer, N., Allouche, A., Koziel, V., Pillot, T., \& Harte, M. K. (2018). Stabilized Low-n Amyloid- Oligomers Induce Robust Novel Object Recognition Deficits Associated with Inflammatory, Synaptic, and GABAergic Dysfunction in the Rat. Journal of Alzheimer's disease : JAD, 62(1), 213-226. https://doi.org/10.3233/JAD-170489

\section{Published in:}

Journal of Alzheimer's disease : JAD

\section{Citing this paper}

Please note that where the full-text provided on Manchester Research Explorer is the Author Accepted Manuscript or Proof version this may differ from the final Published version. If citing, it is advised that you check and use the publisher's definitive version.

\section{General rights}

Copyright and moral rights for the publications made accessible in the Research Explorer are retained by the authors and/or other copyright owners and it is a condition of accessing publications that users recognise and abide by the legal requirements associated with these rights.

\section{Takedown policy}

If you believe that this document breaches copyright please refer to the University of Manchester's Takedown Procedures [http://man.ac.uk/04Y6Bo] or contact uml.scholarlycommunications@manchester.ac.uk providing relevant details, so we can investigate your claim.

\section{OPEN ACCESS}




\title{
Stabilized Low-n Amyloid- $\beta$ Oligomers Induce Robust Novel Object Recognition Deficits Associated with Inflammatory, Synaptic, and GABAergic Dysfunction in the Rat
}

\author{
William Watremez ${ }^{\mathrm{a}}$, Joshua Jackson ${ }^{\mathrm{a}}$, Bushra Almari ${ }^{\mathrm{a}}$, Samantha L. McLean ${ }^{\mathrm{b}}$, Ben Grayson ${ }^{\mathrm{a}}$, \\ Joanna C. Neill ${ }^{\mathrm{a}}$, Nicolas Fischer ${ }^{\mathrm{c}}$, Ahmad Allouche $^{\mathrm{c}}$, Violette Koziel ${ }^{\mathrm{c}}$, Thierry Pillot ${ }^{\mathrm{c}}$ \\ and Michael K. Harte ${ }^{\mathrm{a}, *}$ \\ ${ }^{a}$ Division of Pharmacy and Optometry, University of Manchester, Manchester, UK \\ ${ }^{\mathrm{b}}$ School of Pharmacy and Medical Sciences, University of Bradford, Bradford, UK \\ ${ }^{\mathrm{c}}$ SynAging, Institut Polytechnique National de Lorraine, Vandoeuvre-lès-Nancy, France
}

Accepted 28 November 2017

\begin{abstract}
.
Background: With current treatments for Alzheimer's disease (AD) only providing temporary symptomatic benefits, disease modifying drugs are urgently required. This approach relies on improved understanding of the early pathophysiology of AD. A new hypothesis has emerged, in which early memory loss is considered a synapse failure caused by soluble amyloid- $\beta$ oligomers (Aßo). These small soluble $\mathrm{A} \beta \mathrm{o}$, which precede the formation of larger fibrillar assemblies, may be the main cause of early AD pathologies.

Objective: The aim of the current study was to investigate the effect of acute administration of stabilized low-n amyloid- $\beta_{1-42}$

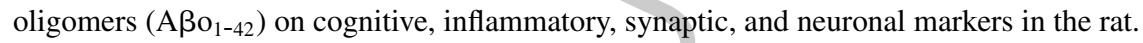

Methods: Female and male Lister Hooded rats received acute intracerebroventricular (ICV) administration of either vehicle or $5 \mathrm{nmol}$ of $\mathrm{A} \beta_{1-42}(10 \mu \mathrm{L})$. Cognition was assessed in the novel object recognition (NOR) paradigm at different time points. Levels of inflammatory (IL-1 $\beta$, IL-6, TNF- $\alpha$ ), synaptic (PSD-95, SNAP-25), and neuronal (n-acetylaspartate, parvalbuminpositive cells) markers were investigated in different brain regions (prefrontal and frontal cortex, striatum, dorsal and ventral hippocampus).

Results: Acute ICV administration of $\mathrm{A} \mathrm{\beta o}_{1-42}$ induced robust and enduring NOR deficits. These deficits were reversed by acute administration of donepezil and rolipram but not risperidone. Postmortem analysis revealed an increase in inflammatory markers, a decrease in synaptic markers and parvalbumin containing interneurons in the frontal cortex, with no evidence of widespread neuronal loss.

Conclusion: Taken together the results suggest that acute administration of soluble low-n A $\beta$ o may be a useful model to study the early mechanisms involved in AD and provide us with a platform for testing novel therapeutic approaches that target the early underlying synaptic pathology.
\end{abstract}

Keywords: Alzheimer's disease, amyloid- $\beta$ oligomers, cognition, parvalbumin interneurons

\footnotetext{
*Correspondence to: Dr. Michael Harte, Room 2.131 - Stopford Building, Division of Pharmacy and Optometry, University of
}

Manchester, Oxford Road, Manchester, M13 9PT, UK. Tel.: +44 01612752 328; E-mail: michael.harte@manchester.ac.uk. 


\section{INTRODUCTION}

Within the Alzheimer's disease (AD) brain, several species of soluble amyloid- $\beta(A \beta)$ can be found, along with insoluble fibrils and plaques, and several attempts at identifying the toxic species of soluble oligomers have been made. It has been demonstrated that following intracerebroventricular injection (ICV) in mice, high molecular weight (HMW; ranging from $\sim 50$ to $\sim 150 \mathrm{kDa}$ ), and low molecular weight (LMW; dimers-tetramers) oligomers act differently, with LMW oligomers causing long lasting, synaptic alterations, and HMW oligomers causing short term NMDA receptor associated cognitive disruption [1]. Other studies have demonstrated a role for LMW oligomers in synaptic loss or dysfunction [2-5]. LMW oligomers have also been shown to induce the collapse of the endoplasmic reticulum (ER) and destabilize microtubules in rat hippocampal cells [6]. ER dysfunction has also been shown in the APPSwe mutant mouse model and human $\mathrm{AD}$ brain $[6,7]$.

The literature surrounding the use of different oligomerizations is vast. This may be down to the large variety of oligomer preparation methods, differences in using either synthetic or purified $A \beta$, or the tendency of $A \beta$ to aggregate spontaneously. While elucidating the role of each type of $A \beta$ oligomer is important, it is also crucial to understand how $A \beta$ oligomers act when in a more physiological mixed form. Protocols also differ in the site, concentration, and volume of administration used.

In the current study, we focused our research on the administration of stabilized low-n amyloid- $\beta_{1-42}$ oligomers ( $\left.\mathrm{A} \mathrm{Bo}_{1-42}\right)$. This peptide is not only one of the main species found in $\mathrm{AD}$, but its stabilized aggregation state facilitates the study of oligomeric forms, thought to have a more potent toxic effect than larger aggregates $[8,9]$. This model is furthermore supported by recent publications using the same species of $\mathrm{A} \mathrm{O}_{1-42}$ in a similar mouse model (SynAging, France), showing cognitive and neuropathological changes of relevance for AD research [10-13].

In the current study, rats received an acute ICV injection of stabilized LMW $\mathrm{A} \beta \mathrm{o}_{1-42}$ composed of dimers, trimers, and tetramers. Novel object recognition (NOR) was performed to access any cognitive changes caused by the oligomers. Long lasting effects on cognition, effect of gender, and pharmacological interventions were assessed. Postmortem studies focused on neuropathological markers (including inflammatory, synaptic, general neuronal, and GABAergic markers), commonly explored in $\mathrm{AD}$ models in regions related to cognitive function.

\section{MATERIALS AND METHODS}

\section{Animals}

Adult female $(n=100,190-230 \mathrm{~g})$ and male $(n=20,250-280 \mathrm{~g})$ Lister Hooded rats (Charles River, UK) aged approximately 3 months old at the time of ICV administration of $\mathrm{A} \mathrm{O}_{1-42}$ were used in the studies. Rats were housed in groups of 45 , in individually ventilated cages with two levels (GR1800 Double-Decker Cage, Techniplast, UK) on a 12-h light-dark cycle, with free access to food and water. Cages were kept in a controlled environment (temperature $21 \pm 2{ }^{\circ} \mathrm{C}$ and humidity $55 \pm 5 \%$ ) in the Biological Services Facility at the University of Manchester. Experiments were conducted during the light cycle, in the morning. All experiments were conducted in accordance with the UK Animals (Scientific Procedures) 1986 Act and University ethical guidelines. A free online power analysis software was used to calculate the sample size required for each group of animals. Calculations were based on the most restrictive test, behavioral tests usually requiring a larger effect size than biochemical analyses. The effect size and standard deviation were estimated from previous studies performed by our laboratory on similar studies. Power calculations were based on a Type 1 error of $5 \%(p=0.05)$. A power of $80 \%$ was set, the direction of the effect was two-tailed and statistical analysis was based on the Student's $t$-test and ANOVA. Results indicated that 10 animals were required per group in order to obtain relevant and significant results in the behavioral tests. The same calculations were made for the postmortem analysis with effect size based on previous in house studies of similar markers.

\section{Experimental design}

\section{Behavioral studies}

For the time-course study (Fig. 1A), animals received $10 \mu \mathrm{L}$ ICV administration of either vehicle ( $n=10$ females) or $\mathrm{A} \beta \mathrm{o}_{1-42} 5 \mathrm{nmol}(n=10$ females). The novel object recognition (NOR) tasks were then performed 4, 14, 35, and 70 days later. These time points were chosen in order to allow enough time for animals to recover from surgery, to allow enough 
time in between each test so animals would complete the task, and to assess the duration of the deficits observed.

The NOR test is extremely useful for identification of cognitive deficits and their neural basis, and for testing the efficacy of novel therapeutic agents in a number of disorders [41]. It is a two-trial cognitive paradigm that assesses recognition memory. Recognition memory is disturbed in a range of human disorders and NOR is widely used in rodents for investigating deficits in a variety of animal models of human conditions where cognition is impaired. In the current study, the NOR task was chosen as it possesses several advantages over more complex tasks that involve lengthy training procedures and/or food or water deprivation. It is quick to administer and allows animals to be retested. It is non-rewarded, provides data quickly, and most importantly, ethologically relevant as it relies on the animal's natural preference for novelty. For the gender study (Fig. 1B), animals received $10 \mu \mathrm{L}$ ICV administration of either vehicle $(n=10$ females, $n=10$ males $)$ or $\mathrm{A} \mathrm{o}_{1-42} 5 \mathrm{nmol}(n=10$ females, $n=10$ males). The NOR task was then performed 4 days later.

For the pharmacological study (Fig. 1C), animals received $10 \mu \mathrm{L}$ ICV administration of either vehicle ( $n=10$ females) or $\mathrm{A} \mathrm{o}_{1-42} 5 \mathrm{nmol}(n=20$ females). The NOR tasks were then performed after acute intraperitoneal (IP) administration of either saline, donepezil $(1 \mathrm{mg} / \mathrm{kg})$, rolipram $(0.01 \mathrm{mg} / \mathrm{kg})$, or risperidone $(0.1 \mathrm{mg} / \mathrm{kg})$, respectively 4,8 , and 14 days later. Pre-treatment times and doses used were determined from previous work in our laboratory in female Lister Hooded rats [42].

\section{Postmortem analysis of inflammatory, synaptic, and neuronal markers}

A separate cohort of animals received $10 \mu \mathrm{L} \mathrm{ICV}$ administration of either vehicle ( $n=15$ females) or $\mathrm{A} \mathrm{o}_{1-42} 5 \mathrm{nmol}(n=15$ females). 14 days later and following NOR testing, $n=5$ in each group were culled for high-performance liquid chromatography (HPLC) analysis of the general neuronal marker, n-acetylaspartate (NAA). 35 days following ICV administration of $\mathrm{A} \beta \mathrm{O}_{1-42}$, the remaining $n=10$ in each group were culled for ELISA analysis of inflammatory (IL-1 $\beta$, IL-6, and TNF- $\alpha$ ) and synaptic (PSD-95 and SNAP-25) markers (Fig. 1D).

Rats from experiment 1 were culled 70 days after ICV administration of $\mathrm{A} \mathrm{O}_{1-42}$, following NOR testing and brains were prepared for immunohistochemical staining for GABAergic parvalbumin-positive interneurons (Fig. 1A).

For postmortem analysis, regions of interest were defined according to the Atlas of Paxinos and Watson in relation to bregma. Brains were dissected on ice (or cut using a cryostat, immunohistochemistry) and the area of interest dissected from 1-2 mm thick slices. Approximate coordinates of the regions investigated were: Frontal cortex, between bregma +5.20 -+3.20 ; prefrontal cortex, between bregma +3.2 and +1.7 ; striatum, between bregma +1.2 and -0.2 ; hippocampus, dorsal, between bregma -2.30 and -3.80 , ventral, between bregma -4.8 and -6.0 ; and temporal cortex, between bregma -2.30 and -3.80 . General neuronal dysfunction (NAA) was assessed in a number of regions of relevance to cognitive function and in relation to regions studied in previous rodent models [43, 44]. Neuroinflammatory, synaptic, and parvalbumin studies were carried out in the frontal cortex and hippocampus (and the prefrontal cortex for parvalbumin). These areas were chosen in relation to previous studies using the same oligomer preparation in the mouse model work by SynAging [11, 12].

\section{Amyloid- $\beta_{1-42}$ oligomer administration}

Rats were randomly assigned into two groups and received $10 \mu \mathrm{L}$ ICV administration of either vehicle or $A \beta_{1-42}$ (5 nmol, SynAging, France) into the left hemisphere. Concentration of oligomers was adapted from previous work conducted by SynAging in mice [10-13]. A $\beta_{1-42}$ preparations largely consist of tetramers, some trimers and residual monomers. They are completely stable when stored frozen. Every preparation was validated in vitro. In vivo, $\mathrm{A} \beta \mathrm{O}_{1-42}$ were used at a dose of $5 \mathrm{nmol}$ (equivalent to the constituent monomer peptide concentration). Briefly, rats were anaesthetized with $4 \%$ isoflurane in $\mathrm{O}_{2}$ (maintained at 2-3\% isoflurane) and placed into a stereotaxic frame. Animals then received a sub-cutaneous administration of $0.1 \mathrm{mg} / \mathrm{kg}$ of buprenorphine. Following an incision in the scalp, a hole was drilled in the skull at the following coordinates, AP: $-0.8 \mathrm{~mm}$ (posterior) and DV: $-1.5 \mathrm{~mm}$ (lateral) from bregma. A needle (Hamilton ${ }^{\circledR} 701 \mathrm{~N}$ ) was gently inserted at $-4.5 \mathrm{~mm}$ (ventral), to reach the left ventricle [14]. Vehicle (phosphate buffered saline) or $\mathrm{A} \beta_{1-42}$ was administrated at a rate of $2.5 \mu \mathrm{L} / \mathrm{min}$. The scalp was sutured and an antibiotic was locally applied. Animals were left to recover in a heated chamber and closely monitored before being returned to their home cage. 


\section{A - Time course + Parvalbumin immunostaining}

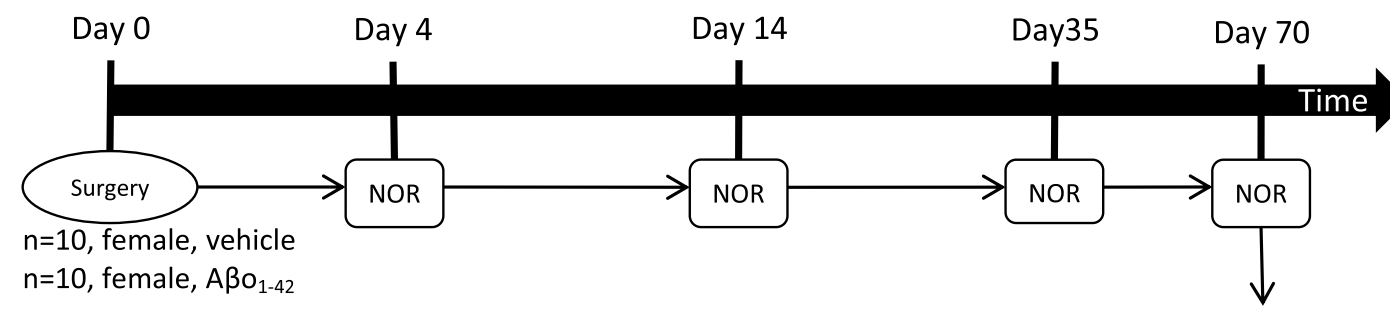

\section{B-Gender specificity}

$\mathrm{n}=20$ parvalbumin

Day

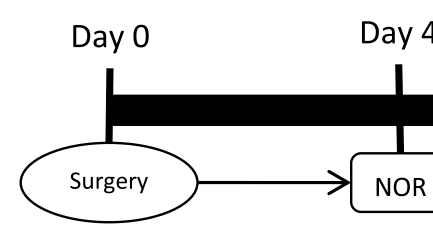

$\mathrm{n}=10$, female, vehicle

$\mathrm{n}=10$, male, vehicle

$\mathrm{n}=10$, female, $A \mathrm{O}_{1-42}$

$\mathrm{n}=10$, male, $A \mathrm{O}_{1-42}$

\section{C-Pharmacological treatment}

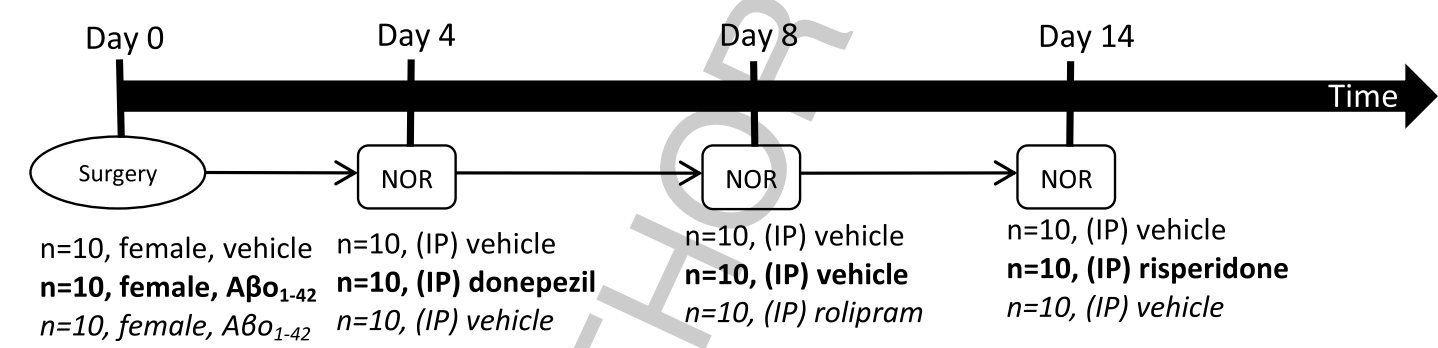

\section{$D$ - Neuropathological markers}

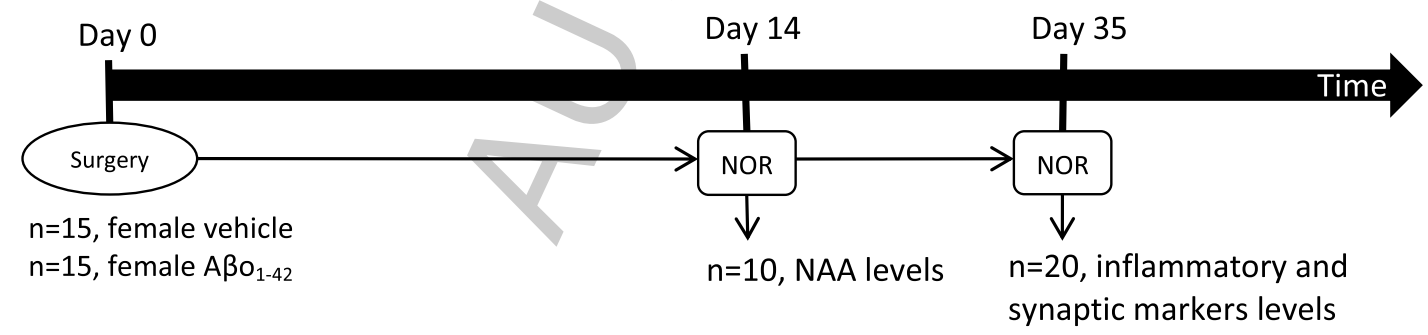

Fig. 1. Outline of the experiments. On the day of surgery (day 0), rats were administrated with $10 \mu \mathrm{L}$ of either vehicle or $\mathrm{A} \beta \mathrm{o}_{1-42}(5 \mathrm{nmol})$. A-C) Experiment 1: Characterization of the cognitive deficit. NOR tasks were performed on days 4, 14, 35, and 70. In study C, rats received an acute IP treatment of vehicle or: donepezil $1 \mathrm{mg} / \mathrm{kg}$ (day 4), rolipram $0.01 \mathrm{mg} / \mathrm{kg}$ (day 8), and risperidone $0.1 \mathrm{mg} / \mathrm{kg}$ (day 14); the $\mathrm{A} \mathrm{O}_{1-42}$ group receiving the treatment was reversed at each time point, allowing a washout of the previous treatment. A, D) Experiment 2: Neuropathological markers. A) Rats from Experiment 1 were culled on day 70 and frontal and prefrontal cortices stained for parvalbuminpositive cells. D) Neuropathological markers. On day $14, n=5$ in each group were culled for N-acetylaspartate analysis. On day $35, n=10$ in each group were culled for inflammatory (IL-1 $\beta$, IL-6, and TNF- $\alpha$ ) and synaptic (SNAP-25, PSD-95) marker analysis.

\section{Behavior}

Cognition was assessed by measuring short-term recognition memory in rats using the NOR task
$[18,24]$. Briefly, animals were habituated to the testing arena with their cage mates on two consecutive days for 30 and $15 \mathrm{~min}$, respectively, prior to the first experimentation. On the day of testing, rats were 
individually placed in a $52 \times 52 \mathrm{~cm}$ box and left free to explore two copies of the same object for $3 \mathrm{~min}$ (acquisition phase). After an inter-trial interval (ITI) of $2 \mathrm{~min}$, the animal was placed back in same box and left free to explore an identical copy of the previously seen object (referred to as the familiar object) and a new object (referred to as the novel object) for another 3 min (retention phase). Time spent exploring both objects was scored in both the acquisition and retention phases, blind to treatment and to the novelty or familiarity of the object. The location of the novel object in the retention trial was randomly assigned for each rat using a pseudo-random Gellerman schedule. Different objects, validated in house, were used for each session. All experiments were filmed and video-recorded for subsequent behavioral analysis by an experimenter blind to the treatments. Object exploration was defined as animals sniffing, licking, or touching the objects with forepaws, but not leaning against, turning around, standing or sitting on the objects. The objects used, their left/right position, and their familiarity/novelty were balanced between animals. Inter-observer reliability of behavioral results was assessed for all experiments.

\section{Parvalbumin immunohistochemistry}

Rats were culled by overdose of anesthetic (5\% isoflurane in $\mathrm{O}_{2}$ ), brains were perfused with phosphate buffered saline (PBS) $0.1 \mathrm{M}$, and perfusion-fixed with $4 \%$ paraformaldehyde in PBS. Brains were rapidly extracted and incubated in $4 \%$ paraformaldehyde for $24 \mathrm{~h}$ followed by $30 \%$ glucose for $48 \mathrm{~h}$ at $4^{\circ} \mathrm{C}$, before being stored at $-80^{\circ} \mathrm{C}$. The frontal cortex and prefrontal cortex were cut and free-floating sections were stained for parvalbumin with a mouse monoclonal anti-parvalbumin antibody (Swant, PV235) and revealed by ABC and DAB kits (Vector Laboratories, PK-6100 and SK4100) as described previously [15]. Sections were mounted on slides, coded, and analyzed blind to treatment. Stained sections were scanned at $4 \mathrm{x}$ magnification using an Olympus BX51 microscope interfaced to an Image ProPlus (version 6.3) analysis system (Media Cybernetics, USA) via a JVC 3-CCD video camera. Estimations of neuronal density $\left(\right.$ cells $/ \mathrm{mm}^{2}$ ) were carried out in every $6^{\text {th }}$ section per region, with a minimum of six sections per animal counted. The region of interest was highlighted and parvalbumin positive neurons were counted live at a higher magnification (20x) using randomly generated points and a
2D counting frame. There was no staining in sections where the primary antibody was omitted.

\section{HPLC analysis of $\mathrm{N}$-acetylaspartate}

Rats were culled by overdose of anesthetic (5\% isoflurane in $\mathrm{O}_{2}$ ), and brains were perfused with PBS $0.1 \mathrm{M}$, rapidly dissected and snap frozen in isopentane before being stored at $-80^{\circ} \mathrm{C}$. The neuronal marker NAA was investigated in six brain regions (frontal cortex, prefrontal cortex, striatum, temporal cortex, dorsal hippocampus, ventral hippocampus). NAA levels were assessed as described previously [16]. Briefly, proteins in the tissue were precipitated with $0.1 \mathrm{M}$ perchloric acid and NAA was extracted from the supernatant using strong anion exchange columns. The extracted sample was analyzed by HPLC (Genesis, C18, $4 \mu \mathrm{m}, 4.6 \mathrm{~mm} \times 250 \mathrm{~mm}$ ), mobile phase $0.1 \%$ phosphoric acid, UV detection $215 \mathrm{~nm}$. NAA levels in each sample were measured by peak height comparison with an external standard curve.

\section{Neuroinflammatory and synaptic markers}

Rats were culled by overdose of anesthetic (5\% isoflurane in $\mathrm{O}_{2}$ ), brains were perfused with PBS 0.1 $M$, rapidly dissected and snap frozen in isopentane before being stored at $-80^{\circ} \mathrm{C}$. Neuroinflammatory (IL-1 $\beta$, IL-6, and TNF- $\alpha$ ) and synaptic (PSD-95 and SNAP-25) markers were investigated in the frontal cortex and the hippocampus. Briefly, samples were homogenized in a sample buffer (Trizma base 0.01 M, sucrose $0.03 \mathrm{M}$, EDTA $0.0025 \mathrm{M}$, PMSF 0.1 $\mathrm{M}$, sodium orthovanadate $0.1 \mathrm{M}$, Protease inhibitor cocktail cOmplete (Roche) tablet), and then centrifuged at $800 \mathrm{~g}$ for $15 \mathrm{~min}$. The supernatant was further centrifuged at $12,000 \mathrm{~g}$ for $20 \mathrm{~min}$. The final supernatant was used to measure inflammatory markers (ELISA kit for IL-1 $\beta / \mathrm{IL}-1 \mathrm{~F} 2$, IL-6 and TNF- $\alpha$, DuoSet), while the final pellet was suspended in PBS $0.1 \mathrm{M}$ for synaptic marker analysis (ELISA kit for DG4 and SNAP-25, Cloud-Clone Corp).

\section{Data analysis}

Results are expressed as mean \pm standard error of the mean (SEM). NOR data were analyzed by ANOVA on repeated measures with object as within-subject factor and group as in-between subject factor. In cases of significance $(p<0.05)$, individual paired samples Student's $t$-tests were run in 
each group, comparing the exploration time of both objects. Total exploration times were analyzed by ANOVA and Bonferroni post-hoc. NAA levels were analyzed by independent samples Mann-Whitney test. Inflammatory markers, synaptic markers and parvalbumin-positive cell density were analyzed by independent samples Student's $t$-tests. All the statistical analyses have been run using IBM SPSS (version 20).

\section{RESULTS}

Stabilized $A \beta \mathrm{O}_{1-42}$ induce a long lasting NOR deficit in the rat (Fig. 2)

In the time course study, on days $4,14,35$, and 70 after ICV administration of $\mathrm{A} \mathrm{O}_{1-42}$, both groups explored both objects equally, in each of the acquisition phases. There was no difference in left/right object exploration $\left[\mathrm{F}_{(1,18)}=2.326 p>0.05\right]$

A - NOR day 4
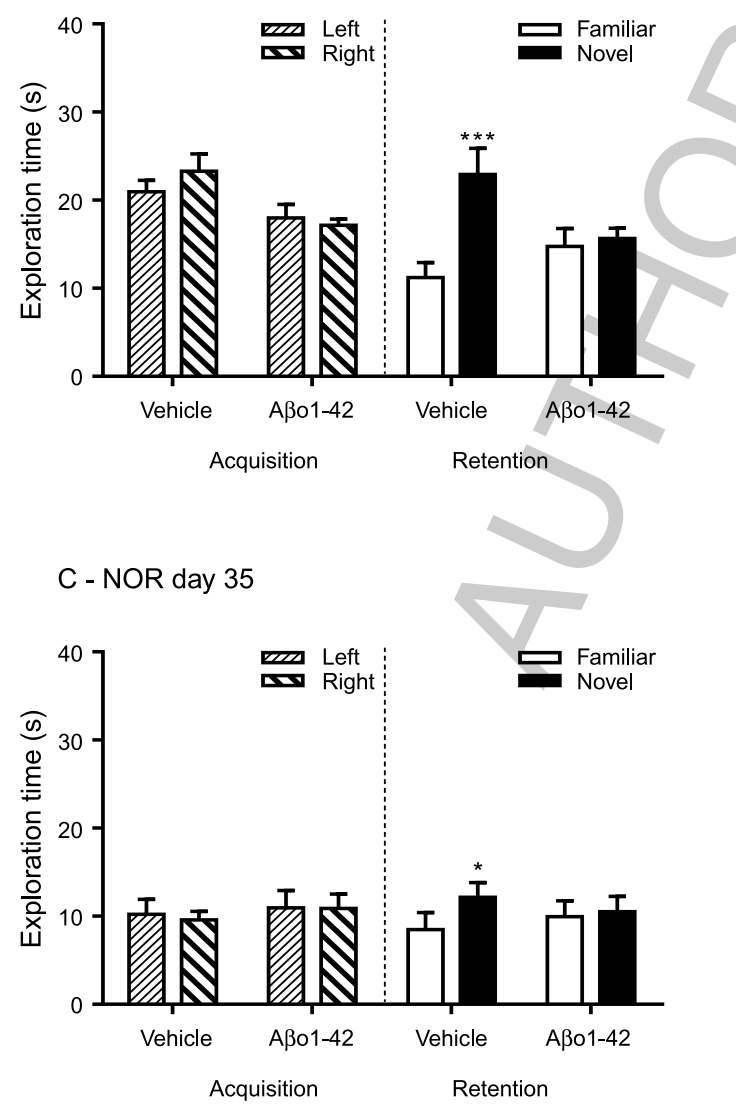

regardless of the day of testing $\left[\mathrm{F}_{(3,16)}=0.496\right.$ $p>0.05]$. Total object exploration was not different between groups $\left[\mathrm{F}_{(1,18)}=1.425 p>0.05\right]$ but was, however, affected by the day of testing $\left[\mathrm{F}_{(3,16)}=47.998 p<0.001\right]$, and was decreased from day 4 to day $14[p<0.001]$ but not on the following sessions $[p>0.05]$.

In the retention phases, there was a significant difference of exploration between the familiar and novel object $\left[\mathrm{F}_{(1,16)}=89.046 p<0.001\right]$ with an effect of group $\left[\mathrm{F}_{(1,16)}=50.249 p<0.001\right]$. The vehicle group spent more time exploring the novel object on day $4\left[\mathrm{t}_{(9)}=-6.244 p<0.001\right]$, day $14\left[\mathrm{t}_{(9)}=-4.923\right.$ $p<0.001]$, day $35\left[\mathrm{t}_{(9)}=-3.180 p<0.05\right]$, and day $70\left[\mathrm{t}_{(9)}=-2.372 p<0.05\right]$. There was, however, no difference in exploration for the $\mathrm{A} \beta \mathrm{o}_{1-42}$ group on any day: day $4\left[\mathrm{t}_{(8)}=-0.715 p>0.05\right]$, day $14\left[\mathrm{t}_{(8)}=-0.890 p>0.05\right]$, day $35\left[\mathrm{t}_{(9)}=-0.251\right.$ $p>0.05]$, and day $70\left[\mathrm{t}_{(9)}=-1.419 p>0.05\right]$. Total object exploration was not different between groups

\section{B - NOR day 14}

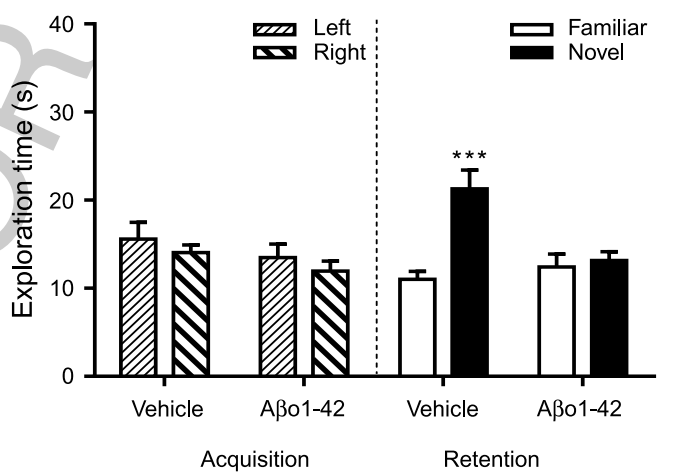

D - NOR day 70

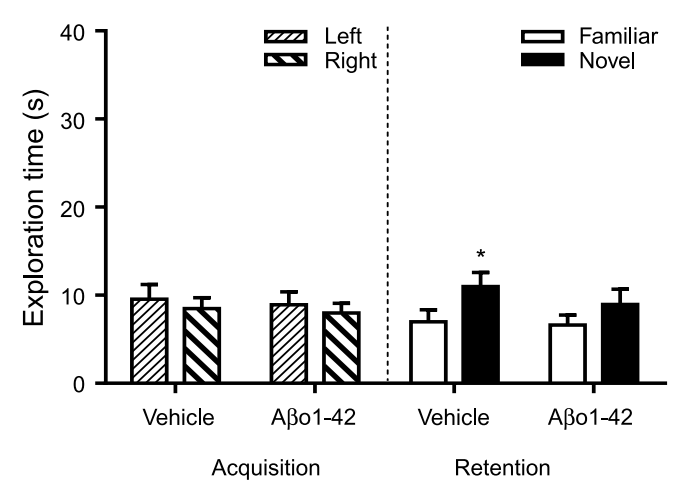

Fig. 2. Experiment 1: Time course. NOR exploration times on day 4 (A), 14 (B), 35 (C), and 70 (D) after ICV administration of vehicle or $\mathrm{A} \beta \mathrm{o}_{1-42}$. Data are presented as mean $+\mathrm{SEM}, n=9-10$ per group. Paired ANOVA and Student's $t$-test, $* p<0.05 * * * p<0.001$ Novel versus Familiar. 


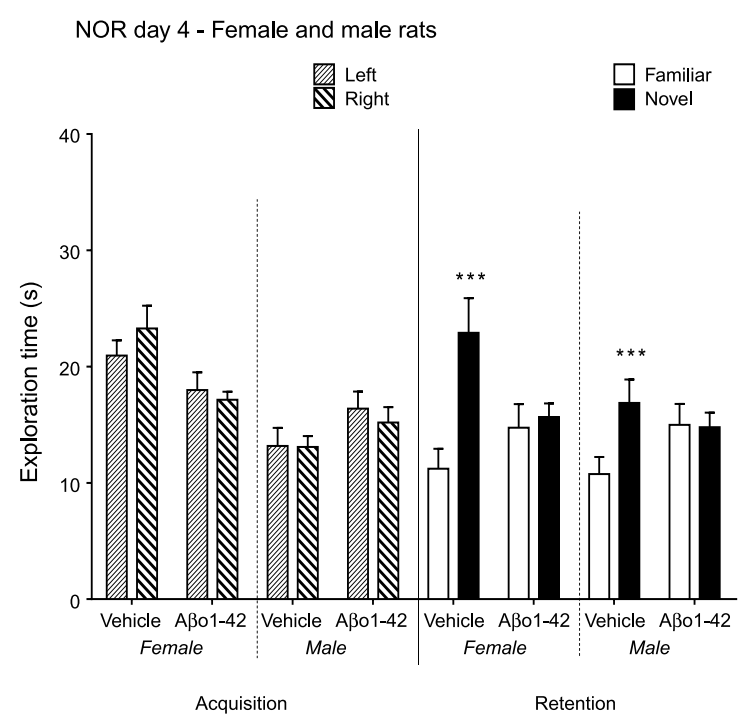

Fig. 3. Experiment 1: Gender specificity. NOR exploration times in both female and male rats, on day 4 after ICV administration of vehicle or $\mathrm{A} \mathrm{Bo}_{1-42}$. Data are presented as mean + SEM, $n=9-10$ per group. Paired ANOVA and Student $t$-test, ${ }^{* * *} p<0.001$ Novel versus Familiar.

$\left[\mathrm{F}_{(1,16)}=2.528 p>0.05\right]$ but was again affected by the day of testing $\left[\mathrm{F}_{(3,14)}=11.216 p<0.001\right]$, and was decreased from day 14 to day 35 only $[p<0.05]$.

In summary, independent of the day of testing, the vehicle group significantly spent more time exploring the novel over the familiar object, an effect that was abolished in the group receiving ICV administration of $\mathrm{A} \beta \mathrm{o}_{1-42}$.

\section{Stabilized $A \beta o_{1-42}$ induce NOR deficits in both} female and male rats (Fig. 3)

In the acquisition phase, all female and male groups explored both objects equally. There was no difference in left/right object exploration $\left[\mathrm{F}_{(1,36)}=0.005 p>0.05\right]$. Total object exploration was not different between vehicle and $\mathrm{A} \beta \mathrm{O}_{1-42}$ groups in each gender sub-group $\left[\mathrm{F}_{(1,36)}=0.663\right.$ $p>0.05]$. However, total object exploration was higher in the female groups when compared to the male groups $\left[\mathrm{F}_{(1,36)}=21.342 p<0.001\right]$.

In the retention phase, there was a significant difference of exploration between the familiar and novel object $\left[\mathrm{F}_{(1,35)}=40.563 p<0.001\right]$ with a significant effect of group $\left[\mathrm{F}_{(1,35)}=34.649 p<0.001\right]$. Both vehicle groups spent significantly more time exploring the novel object, female $\left[\mathrm{t}_{(9)}=-6.244\right.$ $p<0.001]$ and male [ $\left.\mathrm{t}_{(9)}=-4.927 p<0.001\right]$. There was, however, no difference of exploration in both $\mathrm{A} \beta \mathrm{o}_{1-42}$ treated groups, female $\left[\mathrm{t}_{(9)}=-0.715\right.$ $p>0.05]$ and male $\left[\mathrm{t}_{(9)}=0.162 p>0.05\right]$. Total object exploration was not different between animals, regardless of group $\left[\mathrm{F}_{(1,35)}=0.051 p>0.05\right]$ or gen$\operatorname{der}\left[\mathrm{F}_{(1,35)}=1.042 p>0.05\right]$.

In summary, independent of the gender of the rats, vehicle groups spent significantly more time exploring the novel over the familiar object, an effect that was abolished in the groups receiving ICV administration of $\mathrm{A} \mathrm{Bo}_{1-42}$.

Acute treatment with donepezil and rolipram, but not risperidone, rescues the NOR deficit (Fig. 4)

In the acquisition phases, all groups explored both objects equally. There was no difference in left/right object exploration in any group, on each day of testing; respectively $\left[\mathrm{F}_{(1,25)}=0.0001 p>0.05\right]$ on day $4,\left[\mathrm{~F}_{(1,22)}=0.935 p>0.05\right]$ on day 8 , and $\left[\mathrm{F}_{(1,22)}=0.935 p>0.05\right]$ on day 14 after ICV administration of $\mathrm{A} \beta \mathrm{O}_{1-42}$.

In the retention phases, ICV administration of $\mathrm{A} \mathrm{o}_{1-42}$ induced a NOR deficit on each day of testing; an effect that was rescued by acute IP treatment with donepezil $(1 \mathrm{mg} / \mathrm{kg})$ and rolipram $(0.01 \mathrm{mg} / \mathrm{kg})$, but not risperidone $(0.1 \mathrm{mg} / \mathrm{kg})$. All statistical test results are summarized in Table 1.

In summary, vehicle groups spent significantly more time exploring the novel over the familiar object, an effect that was abolished in the groups receiving ICV administration of $A \beta_{1-42}$ and restored by acute IP treatment with donepezil and rolipram but not risperidone.

\section{Stabilized $A \beta o_{1-42}$ induces a deficit in}

parvalbumin-containing interneurons, with no change in the general neuronal marker

$\mathrm{N}$-acetylaspartate (Fig. 5)

Rats from the time-course study were culled following the last NOR session, 70 days after ICV administration of $\mathrm{A} \mathrm{O}_{1-42}$. Parvalbumin positive staining was found throughout the frontal and prefrontal regions with no staining in sections where the primary antibody was omitted (Fig. 6). Parvalbuminpositive cell density was significantly reduced in both the frontal cortex $[\mathrm{t}(16)=3.365 p<0.01]$ and prefrontal cortex $[\mathrm{t}(10.89)=4.008 p<0.01]$ of the $\mathrm{A} \beta \mathrm{O}_{1-42}$ treated animals (Fig. 5A).

In a separate experiment and following confirmation of the NOR deficit (data not shown), levels of the neuronal marker NAA were investigated in 6 regions, 


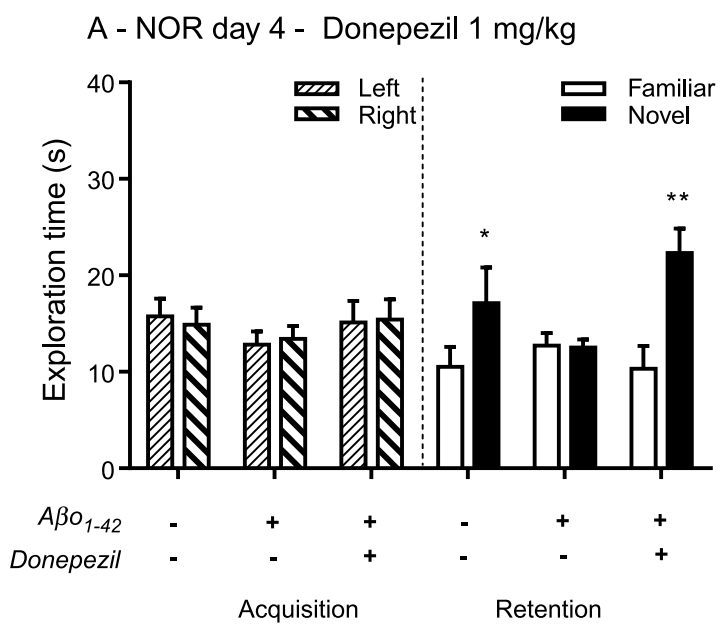

\section{B - NOR day 8 - Rolipram $0.01 \mathrm{mg} / \mathrm{kg}$}
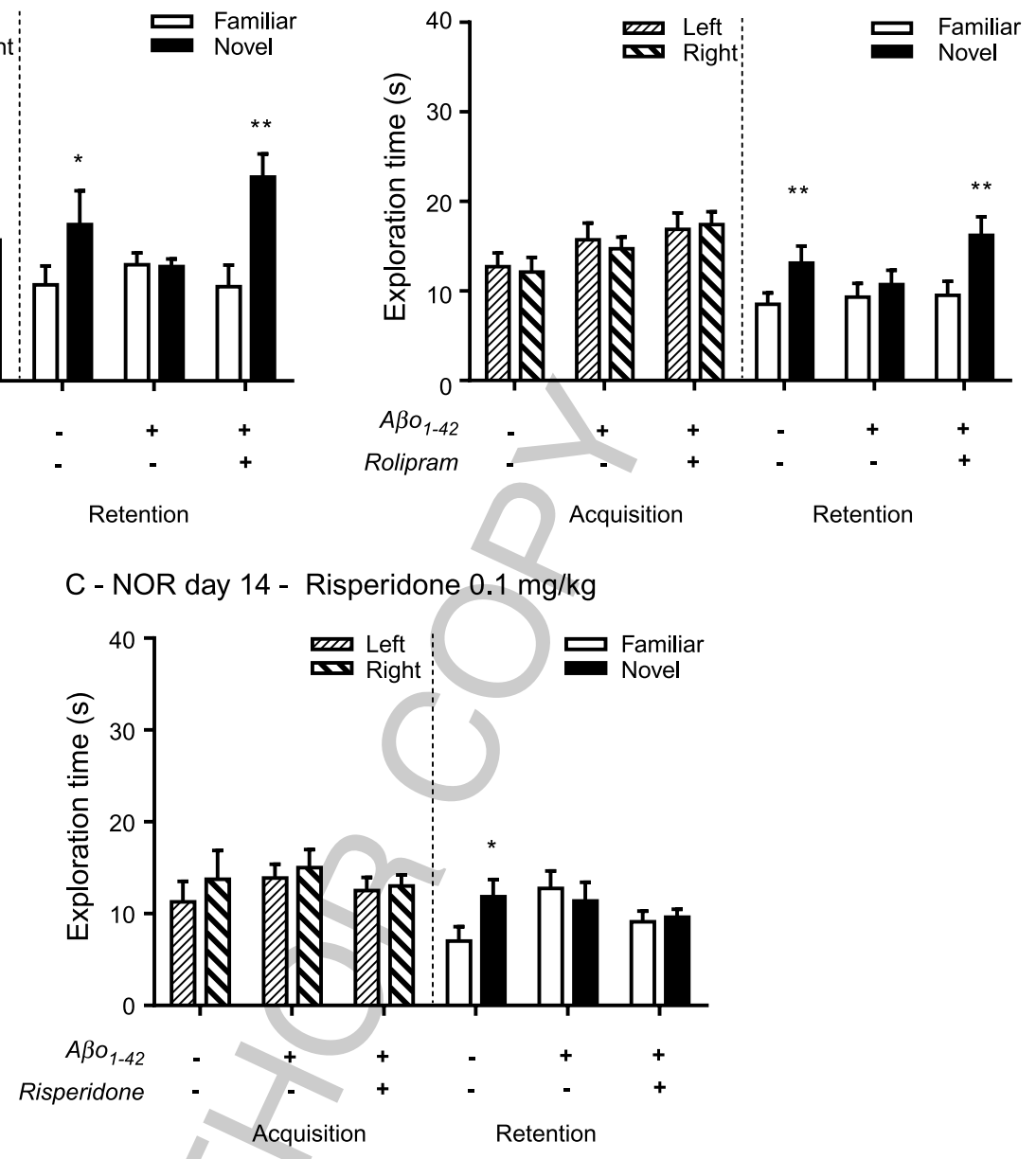

Fig. 4. Experiment 1: Acute pharmacological treatment. NOR exploration times following ICV administration of vehicle or $\mathrm{A} \beta \mathrm{o}_{1-42}$ and acute treatment with donepezil (A), rolipram (B), and risperidone (C). Data are presented as mean + SEM, $n=7-10$ per group. Paired ANOVA and Student $t$-test, ${ }^{*} p<0.05 * * p<0.01$ Novel versus Familiar.

Table 1

Experiment 1: Statistical test results from the NOR retention phases after IP treatment with donepezil, rolipram, and risperidone. Paired ANOVA and Student $t$-test

\begin{tabular}{|c|c|c|c|c|c|c|}
\hline & & \multirow{2}{*}{$\begin{array}{l}\text { Overall difference } \\
\text { in Familiar/Novel } \\
\text { object exploration }\end{array}$} & \multirow[t]{2}{*}{$\begin{array}{c}\text { Overall } \\
\text { group effect }\end{array}$} & \multicolumn{3}{|c|}{$\begin{array}{l}\text { Individual group difference in Familiar/Novel object } \\
\text { exploration }\end{array}$} \\
\hline & & & & Vehicle + Vehicle & $\mathrm{A} \beta \mathrm{o}+$ Vehicle & $\mathrm{A} \beta \mathrm{o}+$ Drug \\
\hline \multirow[t]{4}{*}{ Drug } & $\begin{array}{l}\text { Donepezil } \\
1 \mathrm{mg} / \mathrm{kg}\end{array}$ & $\begin{array}{c}\mathrm{F}_{(1,25)}=24.147 \\
p<0.001\end{array}$ & $\begin{array}{c}\mathrm{F}_{(2,25)}=8.638 \\
p<0.01\end{array}$ & $\begin{array}{c}\text { YES } \\
\mathrm{t}_{(7)}=-2.391 \\
p<0.05\end{array}$ & $\begin{aligned} & \mathrm{NO} \\
\mathrm{t}_{(9)} & =0.210 \\
p & >0.05\end{aligned}$ & $\begin{array}{c}\text { YES } \\
\mathrm{t}_{(9)}=-4.768 \\
p<0.01\end{array}$ \\
\hline & Rolipram & $\mathrm{F}_{(1,27)}=24.818$ & $F_{(2,25)}=3.288$ & YES & NO & YES \\
\hline & $0.01 \mathrm{mg} / \mathrm{kg}$ & $p<0.001$ & $p=0.053$ & $\begin{aligned} \mathrm{t}_{(9)} & =-3.657 \\
p & <0.01\end{aligned}$ & $\begin{aligned} \mathrm{t}_{(9)} & =-0.924 \\
p & >0.05\end{aligned}$ & $\begin{aligned} \mathrm{t}_{(9)} & =-4.137 \\
p & <0.01\end{aligned}$ \\
\hline & $\begin{array}{c}\text { Risperidone } \\
0.1 \mathrm{mg} / \mathrm{kg}\end{array}$ & $\begin{array}{c}\mathrm{F}_{(1,22)}=2.262 \\
p>0.05\end{array}$ & $\begin{array}{c}\mathrm{F}_{(21,22)}=3.973 \\
p<0.05\end{array}$ & $\begin{array}{c}\text { YES } \\
\mathrm{t}_{(6)}=-3.501 \\
p<0.05\end{array}$ & $\begin{aligned} & \mathrm{NO} \\
\mathrm{t}_{(7)} & =0.870 \\
p & >0.05\end{aligned}$ & $\begin{aligned} & \text { NO } \\
\mathrm{t}_{(9)} & =-0.337 \\
p & >0.05\end{aligned}$ \\
\hline
\end{tabular}




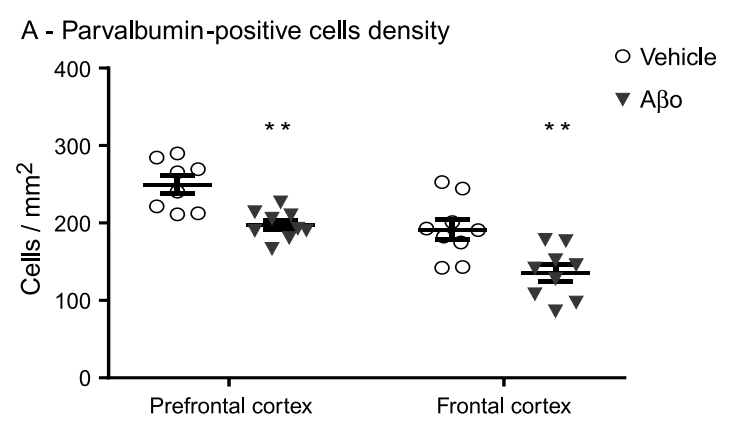

B - NAA level

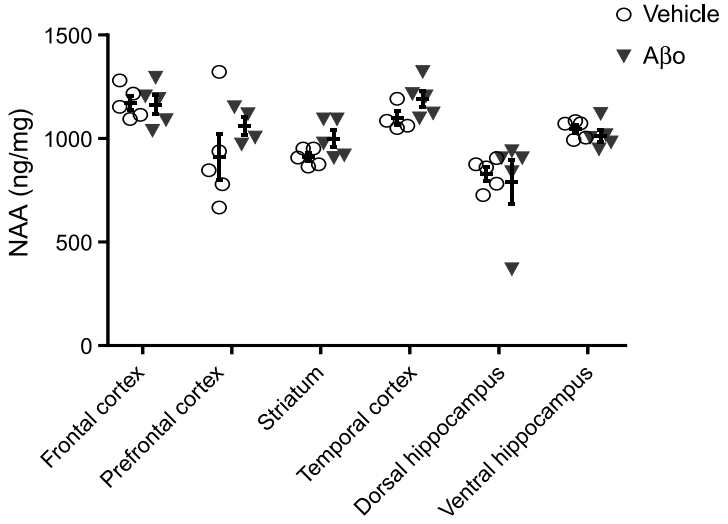

Fig. 5. Experiment 2: A) Results from parvalbumin-positive cell counting in the frontal cortex and prefrontal cortex, 70 days after ICV administration of either vehicle or $\mathrm{A} \beta_{1-42}$. Data are presented as mean \pm SEM, $n=8$-9 per group, independent samples Student's $t$-test, ${ }^{*} p<0.01$ versus Vehicle. B) NAA levels as measured by HPLC across 6 brain areas, 14 days after ICV administration of vehicle or $\mathrm{A} \mathrm{O}_{1-42}$. Data are presented as individual plots, mean \pm SEM, $n=4-5$ per group. Mann-Whitney test, no significant difference between the two groups.

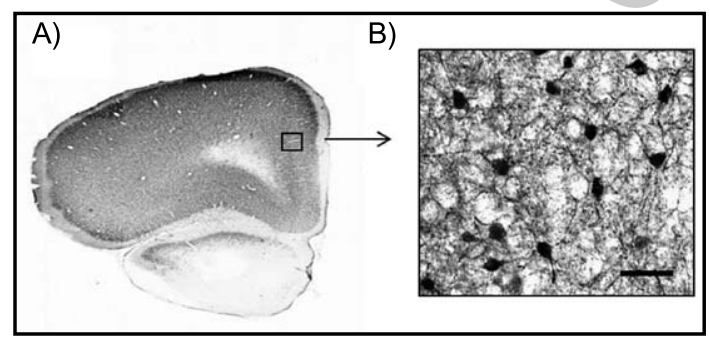

Fig. 6. A) Parvalbumin immunoreactivity in the rat prefrontal cortex. Brightfield photomicrograph of a coronal section showing the distribution of parvalbumin immunoreactivity throughout the hippocampus. $4 \times$ magnification. B) Selected area from (A) of high power $(20 \times$ magnification $)$ brightfield photomicrograph of parvalbumin-immunopositive interneurons in prefrontal cortex. Scale bar $=50 \mu \mathrm{m}$.
14 days after ICV administration of $\mathrm{A} \mathrm{Bo}_{1-42}$. There was no significant difference in the levels of NAA between groups in each of the 6 brain regions investigated (Fig. 5B).

\section{Stabilized $A \beta o_{1-42}$ result in raised levels of the inflammatory markers $I L-1 \beta$ and $T N F-\alpha$ in the frontal cortex (Fig. 7)}

Inflammatory markers IL-1 $\beta$, IL-6, and TNF- $\alpha$ levels were investigated in two regions, frontal cortex and hippocampus, 35 days after ICV administration of $\mathrm{A} \beta \mathrm{O}_{1-42}$, and after confirmation of the NOR deficit (data not shown). There was no difference in the levels of $\mathrm{IL}-1 \beta$ in the hippocampus $\left[\mathrm{t}_{(18)}=-0.451\right.$ $p>0.05]$. In contrast, the level of IL- $1 \beta$ in the frontal cortex was significantly higher in the group administrated with $\mathrm{A} \beta \mathrm{o}_{1-42}\left[\mathrm{t}_{(15)}=-2.694 p<0.05\right]$. There was no difference in the levels of IL-6 in the hippocampus $\left[\mathrm{t}_{(17)}=0.862 p>0.05\right]$ or the frontal cortex $\left[\mathrm{t}_{(16)}=-1.264 p>0.05\right]$. There was no difference in levels of TNF- $\alpha$ in the hippocampus $\left[\mathrm{t}_{(17)}=0.752\right.$ $p>0.05]$. In contrast, levels of TNF- $\alpha$ in the frontal cortex were significantly higher in the group administrated with ${\mathrm{A} \beta \mathrm{o}_{1-42}}\left[\mathrm{t}_{(16)}=-2.299 p<0.05\right]$.

\section{Stabilized $A \beta o_{1-42}$ induce a deficit in the postsynaptic marker PSD-95 in the frontal cortex (Fig. 8)}

Pre- (SNAP-25) and post- (PSD-95) synaptic markers were investigated in two regions, frontal cortex and hippocampus, 35 days after ICV administration of $A \mathrm{O}_{1-42}$ and after confirmation of the NOR deficit (data not shown). There was no difference in levels of SNAP-25 in the hippocampus $\left[\mathrm{t}_{(17)}=1.186\right.$ $p>0.05]$ or the frontal cortex [ $\left.\mathrm{t}_{(16)}=1.908 p>0.05\right]$. There was no difference in levels of PSD-95 in the hippocampus $\left[\mathrm{t}_{(14)}=0.752 p>0.05\right]$. In contrast, levels of PSD-95 in the frontal cortex were significantly lower in the group administrated with $\mathrm{A} \beta \mathrm{O}_{1-42}$ $\left[\mathrm{t}_{(16)}=3.298 p<0.01\right]$.

\section{DISCUSSION}

The current study demonstrated the appearance of a robust and lasting NOR deficit as early as day 4 and up to day 70, and associated with neuropathological changes, following an acute ICV administration of $5 \mathrm{nmol}$ of $\mathrm{A} \mathrm{O}_{1-42}$, in both female and male Lister Hooded rats. Postmortem analysis revealed an increase in inflammatory markers, a decrease 


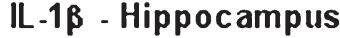

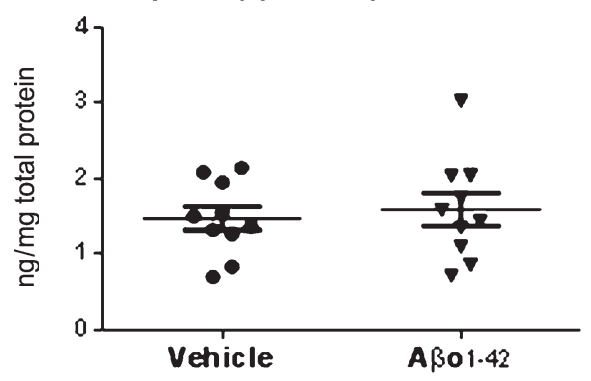

IL 6 - Hippocampus

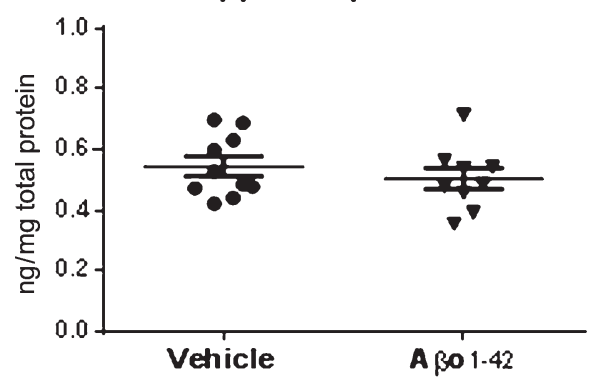

TNF- $\alpha$ - Hip pocampus

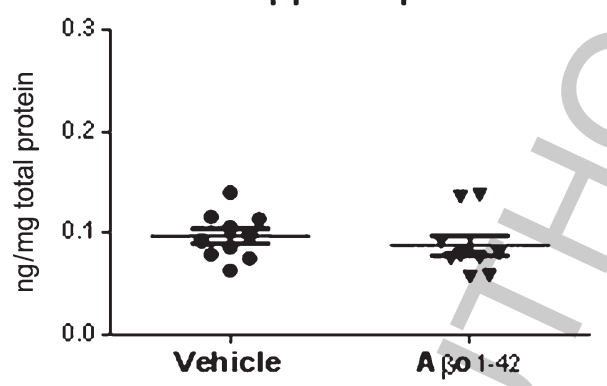

IL-1 $\beta$ - Frontal cortex

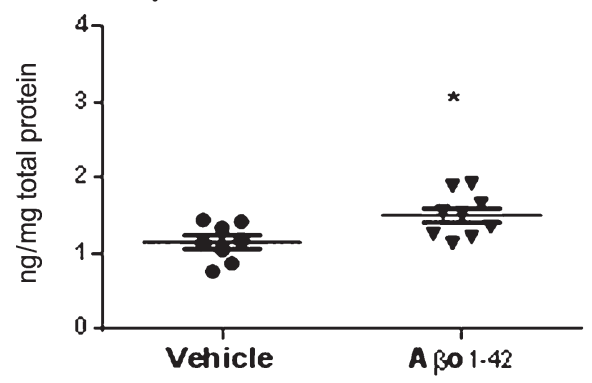

IL 6 - Frontal cortex

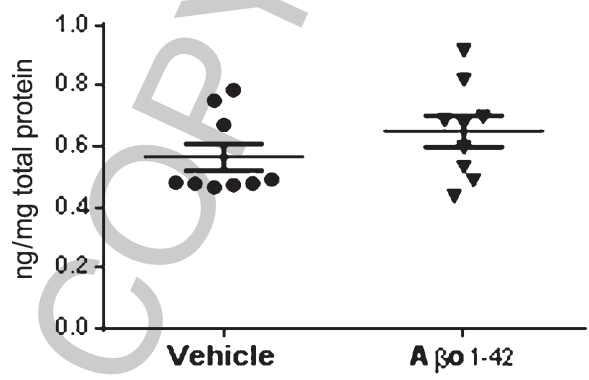

TNF- $\alpha$ - Frontal cortex

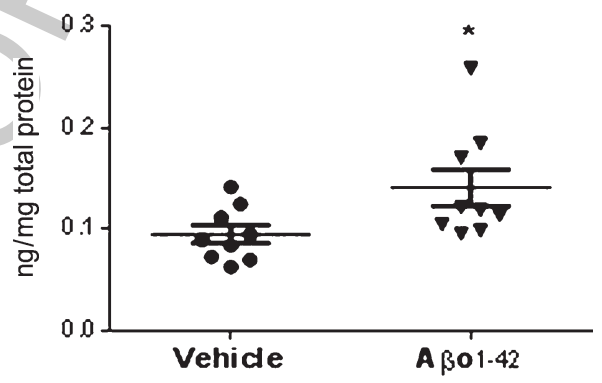

Fig. 7. Experiment 2: Results from the ELISA on neuroinflammatory markers in the hippocampus (left panel) and frontal cortex (right panel), 35 days after ICV administration of vehicle or $\mathrm{A} \beta \mathrm{o}_{1-42}$. Data are presented as individual plots, mean $\pm \mathrm{SEM}, n=8-10$ per group. Independent samples Student's $t$-test, ${ }^{*} p<0.05$ versus Vehicle.

in synaptic markers and parvalbumin containing interneurons in the frontal cortex, with no evidence of widespread neuronal loss.

In successive NOR testing $(4,14,35$, and 70 days following ICV administration of $\mathrm{A} \mathrm{Bo}_{1-42}$ ), both treatment groups showed no difference of exploration time between the identical objects presented during the acquisition phase, a finding which underlines that $\mathrm{A} \beta \mathrm{o}_{1-42}$. did not induce non-specific motor disturbances. In contrast, during the retention phase, only the group administrated with vehicle could perform the task, showing a clear preference for the novel object over the familiar one (Fig. 2A-D). It is, however, noteworthy to observe that in both groups there was an overall decrease in total exploration time over the sessions. In line with previous reports [17], we found that the novelty of the task decreases over time for the rats, lowering their willingness to explore the environment and the objects. We also demonstrated that the $\mathrm{A} \mathrm{O}_{1-42}$ induced NOR deficits appeared to affect both female and male Lister Hooded rats (Fig. 3). Our data support the hypothesis of short-term recognition memory being one of the early cognitive domains affected in our model. These results supplement and confirm cognitive data from a similar mouse model using ICV administration of the same preparation of $A \beta_{1-42}$ (SynAging, France) [10-13]. The SynAging laboratory has found that an ICV injection 

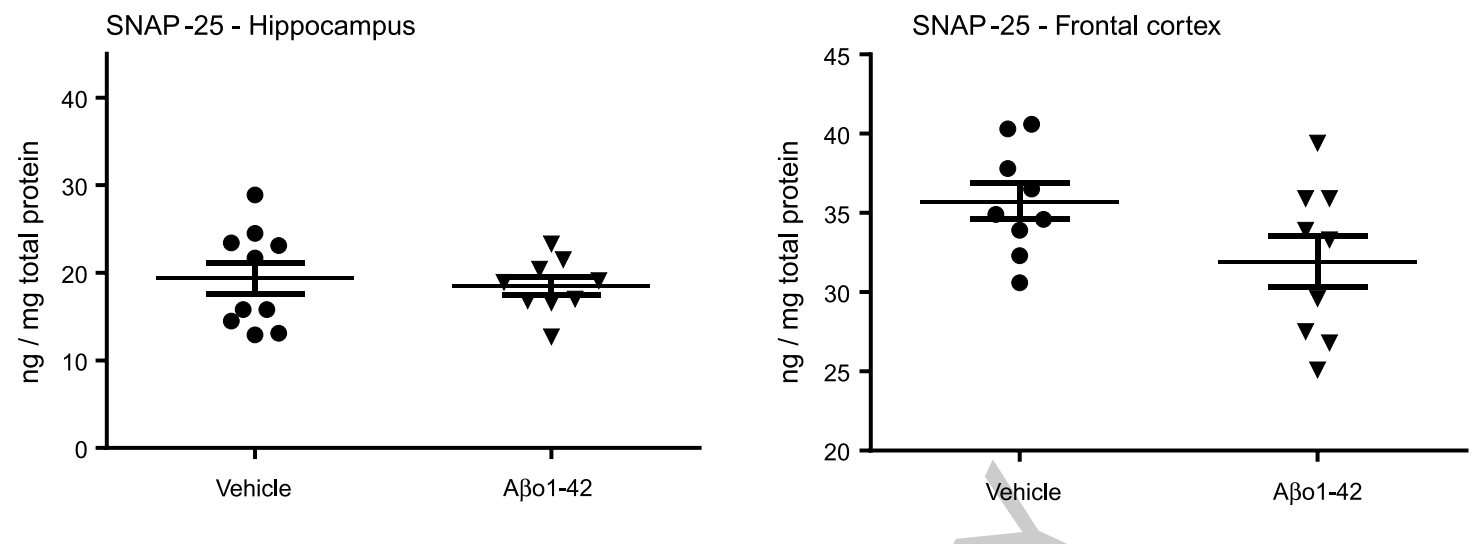

PSD -95 - Hippocampus

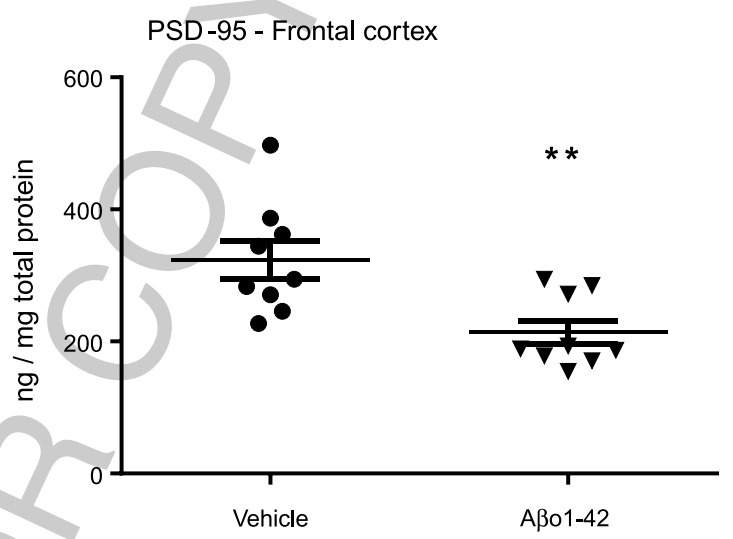

Fig. 8. Experiment 2: Results from the ELISA on synaptic markers in the hippocampus (left panel) and frontal cortex (right panel), 35 days after ICV administration of vehicle or $\mathrm{A} \beta_{\mathrm{o}_{1-42}}$. Data are presented as individual plots, mean $\pm \mathrm{SEM}, n=8-10$ per group. Independent samples Student's $t$-test, ${ }^{* *} p<0.01$ versus Vehicle.

of the same $\mathrm{A} \mathrm{Bo}_{1-42}$ in wild type $\mathrm{C} 57 \mathrm{BL} / 6$ mice induced an impairment in the NOR task (with no effect following administration of the vehicle or the reverse sequence $\mathrm{A} \beta_{42-1}$ ).

The pharmacological experiments demonstrated a reversal of the $A \mathrm{BO}_{1-42}$ induced NOR deficit following acute IP treatment with donepezil $(1 \mathrm{mg} / \mathrm{kg})$ and rolipram $(0.01 \mathrm{mg} / \mathrm{kg})$ but not risperidone (0.1 mg/kg) (Fig. 4).

Donepezil is currently used for the symptomatic treatment of $\mathrm{AD}$ as an acetylcholinesterase inhibitor. Its effect in our model may highlight the presence of a deficit in acetylcholine that the drug could compensate by acutely increasing local levels. We recently demonstrated the ability of donepezil to improve object recognition deficits in a test of "natural forgetting" following a $6 \mathrm{~h}$ ITI in female Lister Hooded rats [18].

Rolipram is a phosphodiesterase-4 (PDE-4) inhibitor, a family of enzymes that regulate the hydrolysis of cAMP and cGMP. These two second messengers are involved in controlling levels of
phospho-cAMP response element-binding (pCREB) in the brain and indirectly playing a role in the modulation of LTP, synaptic plasticity, and memory [19]. Inhibiting PDEs that hydrolyze cGMP could have beneficial effects in dementia [20] and opens new therapeutic possibilities. In line with our findings, other studies in preclinical models with rolipram have shown promising results on restoring cognition in both a mouse transgenic model [21] and a rat model of intra-hippocampal $A \beta o$ administration $[22,23]$.

Risperidone is an atypical antipsychotic used for the treatment of schizophrenia. At lower doses, where you reduce dopamine D2 receptor blockade, we have consistently demonstrated the ability of risperidone to improve cognitive deficits induced by sub-chronic phencyclidine (PCP) in female Lister Hooded (preclinical model of relevance to the cognitive deficits in schizophrenia). We reported improvements in a number of domains including object recognition memory [24], reversal learning [25] and attentional set shifting [26]. In the current study risperidone was unable 
to reverse the deficit in NOR following administration of $A \mathrm{O}_{1-42}$. In line with the finding in the current study, we previously showed that risperidone did not reverse the deficit in NOR in "normal" rats following a $6 \mathrm{~h}$ ITI [18]. Taken together, these studies highlight the different mechanisms that underlie the deficits induced by sub-chronic PCP and $\mathrm{A} \mathrm{Bo}_{1-42}$.

As a result of the study design, different drugs were tested at different, successive time points and we cannot fully rule this out as a potential confound. However, it is of interest to note that the reversal of the NOR deficit in $\mathrm{A} \mathrm{O}_{1-42}$ group was only apparent when the compound was "on-board". The cross-over design of these experiments demonstrated that the behavioral deficit was seen once more in the $\mathrm{A} \mathrm{\beta o}_{1-42}$ group when the compound (donepezil or rolipram) was washed out, demonstrating no carry-over effect on subsequent testing.

These studies highlight the potential benefit of this approach in detecting symptomatic treatments for cognitive deficits in AD but also demonstrate the lack of effect on the underlying pathology responsible for these deficits, indicating the lack of a disease modifying effect.

The density of parvalbumin interneurons was significantly reduced in both the prefrontal and frontal cortices 70 days after acute administration of LMW $\mathrm{A} \mathrm{Bo}_{1-42}$ (Fig. 5A). The reduction of these interneurons is in accordance with studies of human $\mathrm{AD}$ brains, and mouse models of $\mathrm{AD}$, where parvalbumin neurons are known to be reduced [27, 28, 30]. It is plausible that these parvalbumin reductions could be caused by the LMW A $\beta$ oligomers in AD. This would support data that has shown that the altered oscillations in $\mathrm{AD}$, thought to be caused by disrupted inhibitory signaling via parvalbumin interneurons $[29,30]$ occur early in AD [31] at a similar time that LMW oligomers, notably trimers are found to be elevated [32, 33], suggesting this model may present the potential to study the $A \beta$ o mechanisms of relevance to early AD.

NAA is utilized as a non-specific neuronal marker, with changes indicating neuronal loss or dysfunction [34]. The lack of NAA deficits in any of the brain regions investigated, 14 days following ICV administration of $\mathrm{A} \mathrm{Oo}_{1-42}$ (Fig. 5), highlights a lack of widespread non-specific neuronal death, at the concentration of oligomers administrated. One conclusion could be that these oligomers are toxic to only parvalbumin interneurons, or at least only specific neurons, in this model, and that the overall neuronal population is not decreased. However, the difference in time points means any conclusions must be made with caution.

We found increased levels of the neuroinflammatory markers IL- $1 \beta$ and TNF- $\alpha$ in the frontal cortex, 35 days after ICV administration of $A \beta_{1-42}$ (Fig. 7). IL-1 $\beta$ is known to be one of the earliest pro-inflammatory cytokines released following central nervous system insult [35]. Moreover, IL-1 $\beta$ is believed to be an initiator of inflammation, following acute injury [36], with IL- 6 and TNF- $\alpha$ release being delayed in time [37]. However, kinetics data on the mid- and long-term changes in rodent in vivo models of $\mathrm{A} \beta \mathrm{O}$ administration remain an unmet need. In the current study, the presence of increased levels of IL- $1 \beta$ and TNF- $\alpha, 35$ days after administration of $A \beta_{1-42}$, could highlight an underlying phenomenon of constant and lasting inflammation, contributing to the NOR deficit observed at this time point. We also found reduced levels of the postsynaptic marker PSD-95 in the frontal cortex (Fig. 8). $\mathrm{A} \beta \mathrm{o}_{1-42}$ are known to specifically bind to PSD95 positive sites [38]. Decreased levels of PSD-95 are indicative of a disruption of synaptic activity in this area, mirroring the inflammatory changes seen in this region. Taken together, these results suggest decreased synaptic activity associated with neuroinflammation, in the frontal cortex, following ICV administration of $A \beta_{1-42}$ may be contributing to the NOR deficits observed. In support of this is a recent study where we demonstrated the ability of the antiinflammatory mefenamic acid to prevent the NOR deficits following $\mathrm{A} \beta \mathrm{o}_{1-42}$ administration [39].

We found no changes in inflammatory or synaptic markers in the hippocampus in this study, indicating that ICV administration of LMW A $\mathrm{Bo}_{1-42}$ does not have an effect in this region. In line with these findings, spatial memory (as assessed by Y-maze and dependent on hippocampal input) was preserved at day 35 in this model (data not shown). In the current study, we have not been able to track the distribution of the LMW $\mathrm{A} \beta \mathrm{O}_{1-42}$ following administration and so cannot fully explore the specificity of the deficits observed in the frontal cortex over the hippocampus. Brouillette et al. [40] demonstrated that repeated hippocampal injections of small soluble $\mathrm{A} \mathrm{O}_{1-42}$ in awake, freely moving mice were able to induce behavioral (deficits in hippocampus dependent memory) and pathological (marked neuronal loss and tau hyperphosphorylation) deficits or relevance to $\mathrm{AD}$. In acute administration models the site of injection may play an important role in the regions affected. 


\section{Conclusion}

Taken together, these data provide a characterization of the effects of an acute administration of LMW $\mathrm{A} \beta \mathrm{o}_{1-42}$ on cognitive, inflammatory, synaptic, and neuronal markers in Lister Hooded rats. This study adds to the evidence implicating $\mathrm{A} \beta \mathrm{B}$ in $\mathrm{AD}$ and may provide a platform for assessing symptomatic and/ or neuroprotective effects of disease modifying drug candidates.

\section{DISCLOSURE STATEMENT}

Authors' disclosures available online (https:// www.j-alz.com/manuscript-disclosures/17-0489r3).

\section{REFERENCES}

[1] Figueiredo CP, Clarke JR, Ledo JH, Ribeiro FC, Costa CV, Melo HM, Mota-Sales AP, Saraiva LM, Klein WL, Sebollela A, De Felice FG, Ferreira ST (2013) Memantine rescues transient cognitive impairment caused by high-molecularweight $A \beta$ oligomers but not the persistent impairment induced by low-molecular-weight oligomers. J Neurosci 33, 9626-9634.

[2] Chen YR, Glabe CG (2006) Distinct early folding and aggregation properties of Alzheimer amyloid-beta peptides Abeta40 and Abeta42: Stable trimer or tetramer formation by Abeta42. J Biol Chem 281, 24414-24422.

[3] Shankar GM, Bloodgood BL, Townsend M, Walsh DM, Selkoe DJ, Sabatini BL (2007) Natural oligomers of the Alzheimer amyloid-beta protein induce reversible synapse loss by modulating an NMDA-type glutamate receptordependent signaling pathway. J Neurosci 27, 2866-2875.

[4] Townsend M, Shankar GM, Mehta T, Walsh DM, Selkoe DJ (2006) Effects of secreted oligomers of amyloid betaprotein on hippocampal synaptic plasticity: A potent role for trimers. J Physiol 572, 477-492.

[5] Ono K, Yamada M (2011) Low-n oligomers as therapeutic targets of Alzheimer's disease. J Neurochem 117, 19-28.

[6] Lai CS, Preisler J, Baum L, Lee DH, Ng HK, Hugon J, So $\mathrm{KF}$, Chang RC (2009) Low molecular weight $\mathrm{A} \beta$ induces collapse of endoplasmic reticulum. Mol Cell Neurosci 41, $32-43$.

[7] Taguchi J, Fujii A, Fujino Y, Tsujioka Y, Takahashi M, Tsuboi Y, Yamada T (2000) Different expression of calreticulin and immunoglobulin binding protein in Alzheimer's disease brain. Acta Neuropathol 100, 153-160.

[8] Selkoe DJ (2002) Alzheimer's disease is a synaptic failure. Science 298, 789-791.

[9] Jarosz-Griffiths HH, Noble E, Rushworth JV, Hooper NM (2016) Amyloid-beta Receptors: The Good, the Bad, and the Prion Protein. J Biol Chem 291, 3174-3183.

[10] Youssef I, Florent-Bechard S, Malaplate-Armand C, Koziel V, Bihain B, Olivier JL, Leininger-Muller B, Kriem B, Oster T, Pillot T (2008) N-truncated amyloid-beta oligomers induce learning impairment and neuronal apoptosis. Neurobiol Aging 29, 1319-1333.

[11] Garcia P, Youssef I, Utvik JK, Florent-Bechard S, Barthelemy V, Malaplate-Armand C, Kriem B, Stenger C,
Koziel V, Olivier JL, Escanye MC, Hanse M, Allouche A, Desbene C, Yen FT, Bjerkvig R, Oster T, Niclou SP, Pillot T (2010) Ciliary neurotrophic factor cell-based delivery prevents synaptic impairment and improves memory in mouse models of Alzheimer's disease. J Neurosci 30, 7516-7527.

[12] Desbene C, Malaplate-Armand C, Youssef I, Garcia P, Stenger C, Sauvee M, Fischer N, Rimet D, Koziel V, Escanye MC, Oster T, Kriem B, Yen FT, Pillot T, Olivier JL (2012) Critical role of cPLA2 in Abeta oligomer-induced neurodegeneration and memory deficit. Neurobiol Aging 33, 1123 e17-29.

[13] Bouter Y, Dietrich K, Wittnam JL, Rezaei-Ghaleh N, Pillot T, Papot-Couturier S, Lefebvre T, Sprenger F, Wirths O, Zweckstetter M, Bayer TA (2013) N-truncated amyloid beta (Abeta) 4-42 forms stable aggregates and induces acute and long-lasting behavioral deficits. Acta Neuropathol 126, 189205.

[14] Paxinos G, Watson C (1998) The Rat Brain in Stereotaxic Coordinates, Academic Press, New York.

[15] McKibben CE, Jenkins TA, Adams HN, Harte MK, Reynolds GP (2010) Effect of pretreatment with risperidone on phencyclidine-induced disruptions in object recognition memory and prefrontal cortex parvalbumin immunoreactivity in the rat. Behav Brain Res 208, 132-136.

[16] Harte MK, Powell SB, Reynolds LM, Swerdlow NR, Geyer MA, Reynolds GP (2004) Reduced n-acetylaspartate in the temporal cortex of rats reared in isolation. Biol Psychiatry 56, 296-299.

[17] Akkerman S, Blokland A, Reneerkens O, van Goethem NP, Bollen E, Gijselaers HJ, Lieben CK, Steinbusch HW, Prickaerts J (2012) Object recognition testing: Methodological considerations on exploration and discrimination measures. Behav Brain Res 232, 335-347.

[18] McLean SL, Grayson B, Marsh S, Zarroug SH, Harte MK, Neill JC (2016) Nicotinic $\alpha 7$ and $\alpha 4 \beta 2$ agonists enhance the formation and retrieval of recognition memory: Potential mechanisms for cognitive performance enhancement in neurological and psychiatric disorders. Behav Brain Res 302, 73-80.

[19] Garcia-Osta A, Cuadrado-Tejedor M, Garcia-Barroso C, Oyarzabal J, Franco R (2012) Phosphodiesterases as therapeutic targets for Alzheimer's disease. ACS Chem Neurosci 3, 832-844.

[20] Domek-Lopacinska KU, Strosznajder JB (2010) Cyclic GMP and nitric oxide synthase in aging and Alzheimer's disease. Mol Neurobiol 41, 129-137.

[21] Gong B, Vitolo OV, Trinchese F, Liu S, Shelanski M, Arancio O (2004) Persistent improvement in synaptic and cognitive functions in an Alzheimer mouse model after rolipram treatment. J Clin Invest 114, 1624-1634.

[22] Cheng YF, Wang C, Lin HB, Li YF, Huang Y, Xu JP, Zhang HT (2010) Inhibition of phosphodiesterase-4 reverses memory deficits produced by Abeta25-35 or Abeta1-40 peptide in rats. Psychopharmacology 212, 181-191.

[23] Wang C, Yang XM, Zhuo YY, Zhou H, Lin HB, Cheng YF, Xu JP, Zhang HT (2012) The phosphodiesterase-4 inhibitor rolipram reverses Abeta-induced cognitive impairment and neuroinflammatory and apoptotic responses in rats. Int $J$ Neuropsychopharmacol 15, 749-766.

[24] Grayson B, Idris NF, Neill JC (2007) Atypical antipsychotics attenuate a sub-chronic PCP-induced cognitive deficit in the novel object recognition task in the rat. Behav Brain Res 184, 31-38.

[25] McLean SL, Neill JC, Idris NF, Marston HM, Wong EH, Shahid M (2010) Effects of asenapine, olanzapine, and 
risperidone on psychotomimetic-induced reversal-learning deficits in the rat. Behav Brain Res 214, 240-247.

[26] McLean SL, Beck JP, Woolley ML, Neill JC (2008) A preliminary investigation into the effects of antipsychotics on sub-chronic phencyclidine-induced deficits in attentional set-shifting in female rats. Behav Brain Res 189, 152-158.

[27] Brady DR, Mufson EJ (1997) Parvalbumin-immunoreactive neurons in the hippocampal formation of Alzheimer's diseased brain. Neuroscience 80, 1113-1125.

[28] Satoh J, Tabira T, Sano M, Nakayama, H, Tateishi J (1991) Parvalbumin-immunoreactive neurons in the human central nervous system are decreased in Alzheimer's disease. Acta Neuropathol 81, 388-95.

[29] Sohal VS, Zhang F, Yizhar O, Deisseroth K (2009) Parvalbumin neurons and gamma rhythms enhance cortical circuit performance. Nature 459, 698-702.

[30] Verret L, Mann EO, Hang GB, Barth AMI, Cobos I, Ho K, Palop JJ (2012) Inhibitory interneuron deficit links altered network activity and cognitive dysfunction in Alzheimer model. Cell 149, 708-721.

[31] Goutagny R, Gu N, Cavanagh C, Jackson J, Chabot JG, Quirion R, Williams S (2013) Alterations in hippocampal network oscillations and theta-gamma coupling arise before $\mathrm{A} \beta$ overproduction in a mouse model of Alzheimer's disease. Eur J Neurosci 37, 1896-1902.

[32] Lesné S, Koh MT, Kotilinek L, Kayed R, Glabe CG, Yang A, Ashe KH (2006) A specific amyloid-beta protein assembly in the brain impairs memory. Nature 440, 352-357.

[33] Matsumura S, Shinoda K, Yamada M, Yokojima S, Inoue M, Ohnishi T, Hoshia M (2011) Two distinct amyloid $\beta$ protein $(A \beta)$ assembly pathways leading to oligomers and fibrils identified by combined fluorescence correlation spectroscopy, morphology, and toxicity analyses. J Biol Chem 286, 11555-11562.

[34] Martinez MA, Florenzano NV, Macchia EA (2016) Metabolism of $\mathrm{N}$-acetyl-L-aspartate: Its diagnostic and prognostic value. Rev Neurol 62, 361-370.

[35] Griffin WS, Sheng JG, Royston MC, Gentleman SM, McKenzie JE, Graham DI, Roberts GW, Mrak RE (1998) Glial-neuronal interactions in Alzheimer's disease: The potential role of a "cytokine cycle" in disease progression. Brain Pathol 8, 65-72.
[36] Shaftel SS, Griffin WST, O'Banion MK (2008) The role of interleukin-1 in neuroinflammation and Alzheimer disease: An evolving perspective. J Neuroinflammation 5, 7.

[37] Rosales-Corral S, Tan DX, Reiter RJ, Valdivia-Velazquez M, Acosta-Martinez JP, Ortiz GG (2004) Kinetics of the neuroinflammation-oxidative stress correlation in rat brain following the injection of fibrillar amyloid-beta onto the hippocampus in vivo. J Neuroimmunol 150, 20-28.

[38] Lacor PN, Buniel MC, Chang L, Fernandez SJ, Gong Y, Viola KL, Lambert MP, Velasco PT, Bigio EH, Finch CE, Krafft GA, Klein WL (2004) Synaptic targeting by Alzheimer's-related amyloid beta oligomers. J Neurosci 24, 10191-10200.

[39] Daniels MJD, Rivers-Auty J, Schilling T, Spencer NG, Watremez W, Fasolino V, Booth SJ, White CS, Baldwin AG, Freeman S, Wong R, Latta C, Yu S, Jackson J, Fischer N, Koziel V, Pillot T, Bagnall J, Allan SM, Paszek P, Galea J, Harte MK, Eder C, Lawrence CB, Brough D (2016) Fenamate NSAIDs inhibit the NLRP3 inflammasome and protect against Alzheimer's disease in rodent models. Nat Commun 7, 12504.

[40] Brouillette J, Caillierez R, Zommer N, Alves-Pires C, Benilova I, Blum D, De Strooper B, Buée L (2012) Neurotoxicity and memory deficits induced by soluble lowmolecular-weight amyloid- $\beta 1-42$ oligomers are revealed in vivo by using a novel animal model. $J$ Neurosci 32, 78527861.

[41] Grayson B, Leger M, Piercy C, Adamson L, Harte M, Neill JC (2015) Assessment of disease-related cognitive impairments using the novel object recognition (NOR) task in rodents. Behav Brain Res 285, 176-193.

[42] Snigdha S, Horiguchi M, Huang M, Li Z, Shahid M, Neill JC, Meltzer HY (2010) Attenuation of phencyclidineinduced object recognition deficits by the combination of atypical antipsychotic drugs and pimavanserin (ACP 103), a 5-hydroxytryptamine(2A) receptor inverse agonist. J Pharmacol Exp Ther 332, 622-631.

[43] Cohen SJ, Stackman RW Jr (2015) Assessing rodent hippocampal involvement in the novel object recognition task. Behav Brain Res 285, 105-117.

[44] Warburton EC, Brown MW (2015) Neural circuitry for rat recognition memory. Behav Brain Res 285, 131-139. 